\title{
Assessment of wheat varieties for slow rusting and management of stripe rust caused by Puccinia striiformis
}

\author{
SEETHIYA MAHAJAN ${ }^{1}$, VISHAL GUPTA ${ }^{1 *}$, V.K. RAZDAN ${ }^{1}$, KAUSAR FATIMA $^{1}$ and SATISH SHARMA ${ }^{2}$ \\ ${ }^{1}$ Division of Plant Pathology, Faculty of Agriculture, ${ }^{2}$ Seed Multiplication Farm, Sher-e-Kashmir University of Agricultural Sciences \\ and Technology of Jammu, Chatha 180 009, Jammu \& Kashmir, India
}

Received: 27 April 2017/ Accepted: 21 May 2017/ Published online: 25 May 2017

(C) Indian Phytopathological Society 2017

\begin{abstract}
Fifty wheat varieties were screened under artificial epiphytotic conditions against stripe rust of wheat during Rabi, 2013-14. On the basis of final rust severity (FRS), AURPC (Area Under Rust Progress Curve), $r$ (Infection Rate) and CI (Coefficient of Infection), 10 lines exhibited partial resistance against the disease. PCR profiles of 50 wheat varieties by the allele-specific primer (cssfr1) revealed distinct fragment of 517 bp in 23 varieties indicating the presence of Yr18 gene. Wheat varieties, PBW 343, DPW 621-50, RSP 561 and HD 2967 were used for testing five fungicides viz., Amistar Top, Quadrix, Score, Folicur and Tilt, each at $0.1 \%$. Amistar Top was found to be most effective in reducing the disease severity of stripe rust in PBW 343, followed by Quadrix, Score, Folicur and Tilt. The application of these fungicides also showed a significant increase in the grain yield, with maximum increase (33.58\%) by Amistar Top in HD 2967 followed by Quadris, Score, Folicur and Tilt.
\end{abstract}

Keywords: cssfr1, fungicides, Puccinia striiformis, stripe rust, wheat

There were recurrent epidemics of stripe rust of wheat in northern western plain zone of India and occurrence of new virulent pathotypes coupled with the susceptibility of cultivars responsible for a significant reduction in grain yield of wheat (Prashar et al., 2007). The disease affects wheat plant through damaging its respiratory system, reduction in photosynthetic area, stunted growth and most importantly reduced grain yield and test weight by shrivelling of grain (Chen, 2005). Losses in the yield of wheat due to stripe rust primarily depend on the level of susceptibility, environmental conditions and the stage of infection (Singh et al., 2002).

Cultivation of resistant varieties is one of the most feasible methods to manage stripe rust which has no human health and environmental hazardous concerns (Chen, 2007; Farrokhi et al., 2011). Although deployment of race-specific resistance genes ensures effective protection against rust diseases (Shah et al., 2010) but they remain effective only for a few years (Lagudah et al., 2009), whereas, race-non-specific resistance or slow rusting or partial resistance appeared polygenic and durable (Herrere-Fossel et al., 2007). The Lr34/Yr18 gene which confers race-non specific, partial and slow rusting to rusts has appeared effective for the breeding of resistant varieties. Marker csLV34 closely linked to the Lr34/Yr18 locus have been shown to be specific diagnostic tools for this multi-pathogen resistance trait (Lagudah et al., 2006). But on the appearance of the disease in the field, application of synthetic fungicides

${ }^{*}$ Corresponding author: vishal94gupta @ rediffmail.com are widely advocated (Gupta et al., 2013; Selvakumar et al., 2014). Keeping in view these facts, experiments were conducted to evaluate the varieties for slow rusting resistance (genotypic and phenotypic) and also to study the effect of different fungicides in the management of stripe rust in different varieties.

\section{MATERIALS AND METHODS}

The investigations on the characterization of wheat varieties for slow rusting resistance against Puccinia striiformis and management with fungicides were carried out during rabi season of 2013-2015 in the Division of Plant Pathology, Sher-e-Kashmir University of Agricultural Sciences and Technology of Jammu, Chatha. Materials and methods used for conducting experiments are described as:

\section{Screening of wheat varieties}

Fifty wheat varieties (SONORA 64, DWR 16, PBW 343, HD 2281, DURGAPUR 65, VL 616, DBW 16, WH 542, WH 711, GW 496, VL 421, K65, UP 2121, CPAN 3004, RSP 561, HD 2687, HD 2307, SARBATI SONORA, PBW 175, HD 2404, HD 2135, DBW 621-50, HS 240, PBW 373, JAUW 584, HW 2045, RAJ 1482, WH 533, RAJ 821, UP1109, PBW 550, UP 2425, VL 804, LAL BAHADUR, DBW 17, HW 2004, VL 404, HD 2824, PBW 443, WH 1105, SONALIKA, PBW 154, AGRA LOCAL, NP 715, HD 2967, RAJ 3077, RAJ 3765, KALYAN SONA, HD 2329 and HD 2864) were screened against stripe rust under artificial epiphytotic conditions at University 
Research Farm, Chatha. The varieties were sown in rows $(2.0 \mathrm{~m})$ with spacing of $22.5 \mathrm{~cm}$ apart in the first week of November 2013. The whole of the experimental area was surrounded by the susceptible wheat variety (PBW-343). Inoculation of wheat varieties was carried out after 30 days of sowing by urediospore suspension having mixed pathotypes of $P$. striiformis collected from Regional Rust Research Centre (ICAR), Flowerdale, Shimla (H.P.). Data on Final rust severity (FRS), Coefficient of infection (CI), apparent infection rate $(r)$ and AURPC (Area Under Rust Progress Curve) was recorded (Pathan and Park, 2006)

\section{Molecular characterization of Yr18 locus}

Molecular characterization of 50 wheat varieties for $Y r 18$ locus was carried out by using allele-specific markers viz., cssfr1 (F=TTGATGAAACCAGTTTTTTTTCTA; $\mathrm{R}=\mathrm{GCCATTTAACATAATCATGATGGA).} \mathrm{DNA} \mathrm{extractions,}$ purification and quantification were carried out at the twoleaf stage from each variety. Polymerase chain reaction (PCR) amplification by using the above primer was conducted with temperature profiles as described by Seah et al. (1998). The amplification products were separated on $3 \%$ agarose gels containing ethidium bromide and $1 \times$ TBE buûer. The gels were visualized using gel documentation system for documentation of allele type in selected variety.

\section{Management by synthetic fungicides}

Four wheat varieties (PBW 343, DPW 621-50, RSP 561 and HD 296) were selected based upon their susceptibility response against the stripe rust, sown in experimental plot having $3 \mathrm{~m}^{2}$ size consisting of 15 rows, each $2.0 \mathrm{~m}$ long and $22.5 \mathrm{~cm}$ apart during first fortnight of November, 2013-2015. The experiment was laid out in factorial randomized block design with four replications. Five different fungicides viz., Amistar Top (Azoxystrobin18.2\% + Difenoconazole SC), Quadrix (Azoxystrobin$22.9 \%$ SC), Score (Difenoconazole 25 EC), Folicur (Tebuconazole 250 EC) and Tilt (Propiconazole 25 EC) @ 0.1 per cent concentration were tested for their effectiveness in managing stripe rust in different varieties. A control plot of each variety (with water only) was kept for each treatment. A single spray of respective fungicides was done in the first week of February after the appearance of stripe rust symptoms. Observations regarding disease severity were recorded (at 10 days interval) on the basis of modified Cobb's scale (Peterson et al., 1948) and yield/plot in each treatment was recorded after harvest. The data obtained was statistically analyzed and critical difference (CD) at level $p=0.05$ was worked out.

\section{RESULTS AND DISCUSSION}

\section{Screening of wheat varieties for slow rusting resistance against $\boldsymbol{P}$. striiformis}

The data presented in Table 1 revealed that based on FRS (Final Rust Severity), the varieties were categorized into 3 group having low level (1-35\%), moderate (36-
Table 1. Screening of wheat varieties against stripe rust of wheat

\begin{tabular}{|c|c|c|c|c|}
\hline Varieties & ${ }^{*} \mathrm{FRS}$ & ${ }^{* *}$ AURPC & ${ }^{* *} r$ & ${ }^{* * *} \mathrm{Cl}$ \\
\hline AGRA LOCAL & 90 & 2325 & 0.135 & 70.00 \\
\hline CPAN 3004 & 40 & 1425 & 0.101 & 32.00 \\
\hline DBW 16 & 40 & 850 & 0.098 & 32.00 \\
\hline DBW 17 & 50 & 1675 & 0.129 & 50.00 \\
\hline DPW 621-50 & 40 & 1195 & 0.069 & 42.00 \\
\hline DWR 16 & 60 & 1825 & 0.149 & 60.00 \\
\hline DURGAPUR 65 & 40 & 1675 & 0.129 & 50.00 \\
\hline GW 496 & 42 & 1775 & 0.136 & 60.00 \\
\hline HD 2329 & 30 & 750 & 0.071 & 25.00 \\
\hline HS 240 & 40 & 900 & 0.120 & 32.00 \\
\hline HD 2307 & 25 & 750 & 0.132 & 10.00 \\
\hline HD 2824 & 50 & 1000 & 0.114 & 50.00 \\
\hline HD 2864 & 30 & 650 & 0.081 & 39.00 \\
\hline HD 2967 & 20 & 400 & 0.098 & 8.00 \\
\hline HD 2404 & 40 & 1325 & 0.099 & 45.00 \\
\hline HD 2281 & 30 & 800 & 0.116 & 32.00 \\
\hline HD- 2135 & 40 & 1550 & 0.137 & 55.00 \\
\hline HD 2687 & 40 & 1850 & 0.133 & 65.00 \\
\hline HW 2004 & 40 & 950 & 0.145 & 32.00 \\
\hline HW 2045 & 40 & 850 & 0.076 & 32.00 \\
\hline JAUW 584 & 50 & 1000 & 0.114 & 50.00 \\
\hline KALYAN SONA & 45 & 1325 & 0.099 & 45.00 \\
\hline K 65 & 25 & 1025 & 0.127 & 32.00 \\
\hline LAL BAHADUR & 25 & 275 & 0.092 & 10.00 \\
\hline NP 715 & 40 & 1000 & 0.127 & 32.00 \\
\hline PBW 154 & 40 & 700 & 0.075 & 30.00 \\
\hline PBW 175 & 31 & 1005 & 0.124 & 24.80 \\
\hline PBW 343 & 90 & 2325 & 0.135 & 70.00 \\
\hline PBW 443 & 65 & 1800 & 0.127 & 45.00 \\
\hline PBW 550 & 65 & 1850 & 0.165 & 65.00 \\
\hline PBW 373 & 65 & 2125 & 0.123 & 60.00 \\
\hline RAJ 821 & 40 & 400 & 0.098 & 8.00 \\
\hline RSP 561 & 65 & 1375 & 0.118 & 65.00 \\
\hline RAJ 1482 & 80 & 2225 & 0.069 & 65.00 \\
\hline RAJ 3077 & 15 & 225 & 0.041 & 6.00 \\
\hline RAJ 3765 & 70 & 1800 & 0.124 & 65.00 \\
\hline SONALIKA & 40 & 1175.25 & 0.078 & 28.00 \\
\hline SARBATI SONORA & 40 & 1150 & 0.105 & 32.00 \\
\hline SONORA 64 & 45 & 950 & 0.145 & 32.00 \\
\hline UP 2425 & 31 & 1005 & 0.124 & 24.80 \\
\hline UP 1109 & 40 & 1850 & 0.133 & 30.00 \\
\hline UP 2121 & 30 & 745 & 0.114 & 10.00 \\
\hline VL 404 & 40 & 850 & 0.116 & 65.00 \\
\hline VL 616 & 20 & 800 & 0.098 & 32.00 \\
\hline VL 804 & 25 & 625 & 0.063 & 10.00 \\
\hline VL 421 & 35 & 865 & 0.114 & 10.00 \\
\hline WH 542 & 45 & 1350 & 0.075 & 35.00 \\
\hline WH 533 & 25 & 275 & 0.092 & 10.00 \\
\hline WH 711 & 40 & 1575 & 0.143 & 30.00 \\
\hline WH 1105 & 40 & 1235 & 0.118 & 65.00 \\
\hline
\end{tabular}

\footnotetext{
${ }^{*}$ FRS $=$ Final rust severity, ${ }^{*}$ Area Under Rust Progress Curve,
}

${ }^{* * *}$ Coefficient of infection, ${ }^{* * *} r=$ infection rate 
$65 \%$ ) and high (66-90\%) of FRS. Fifteen varieties viz., VL 616, HD 2329, VL 804 , HD 2307, HD 2967, RAJ 3077, HD 2864, LAL BAHADUR, UP 2425, WH 533, UP2121, PBW 175, K 65, HD 2281 and VL 421 exhibited low FRS (1-35\%), while thirty-one varieties (RAJ 821 , RSP 561, JAUW 584, HS 240, PBW 550, HD 2824, WH 542, KALYAN SONA, CPAN 3004, SONALIKA, SARBATI SONORA, DBW 17, HW 2004, DBW16, DPW 621-50, DWR 16, NP 715, GW 496, UP- 1109, HD 2135, WH 711, WH 1105, PBW 443, VL 404, PBW 154, SONORA 64, HD 2987, DURGAPUR 65, HW 2045, PBW 373 and HD2404) having moderate FRS (36-65\%), whereas four varieties viz., AGRA LOCAL, RAJ 1482, RAJ 3765 and PBW 343 showed high FRS of $61-90 \%$. Data further showed that thirteen varieties viz., RAJ 821, VL 616, HD 2329, VL 804, HD 2307, RAJ 3077, HD 2864, HD 2967, LAL BAHADUR, WH 533, PBW 154, UP 2121 and HD 2281) were grouped together having value of AURPC range (0-800), while 25 varieties (RSP 561, JAUW 584, HS 240, HD 2824, WH 542, KALYAN SONA, CPAN 3004, SONALIKA, SARBATI SONORA, HW 2004, DBW 16, DPW 621-50, UP 2425, DWR 16, NP 715, HD 2135, WH 711, WH 1105, VL 404, SONORA 64, PBW 175, HW 2045, K 65, HD 2404 and VL 421) exhibited AURPC value of 800-1600, whereas twelve varieties (RAJ 1482, PBW 550, AGRA LOCAL, DBW 17, GW 496, UP 1109, PBW 443, DURGAPUR 65, RAJ 3765, PBW 373 and PBW 343 showed high value of AURPC (1600-2400). Data on disease severity and host reaction was combined to calculate coefficient of Infection $(\mathrm{Cl})$ which showed that twenty eight varieties (RAJ 821, VL 616, HD 2329, HS 240, VL 804, HD 2307, WH 542, RAJ 3077, HD 2967, CPAN 3004, SONALIKA, SARBATI SONORA, LAL BAHADUR, HW 2004, DBW 16, UP 2425, NP 715, WH 533, UP 1109, WH 711, PBW 154, SONORA 64, UP 2121, PBW 175, HW 2045, K 65, HD 2281 and VL 421) showed $\mathrm{Cl}$ value of 1-35, while 22 varieties (RSP 561 , RAJ 1482, JAUW 584, PBW 550, AGRA LOCAL, HD 2824, KALYAN SONA, HD 2864, PBW 343, DBW 17, DPW 621-50, DWR 16, GW 496, HD 2135, WH 1105, PBW 443, VL 404, HD 2687, DURGAPUR 65, RAJ 3765 , PBW 373 and HD 2404) showed $C l$ value of 36-70. Infection rate ' $r$ ' of 50 varieties varied from 0.020-0.169. Among them, RAJ 3077 exhibited ' $r$ ' of 0.041 , whereas seventeen varieties (RAJ 821, VL 616, HD 2329, RAJ 1482, VL 804, WH 542, KALYAN SONA, HD 2864, HD 2967, SONALIKA, LAL BAHADUR, DBW 16, DPW 62150, WH533, PBW 154, HW 2045 and HD2404 showed value of ' $r$ ' between $0.050-0.100$, while 32 varieties (RSP 561, JAUW 1482, HS 240, PBW 550, AGRA LOCAL, HD 2824, HD 2307, PBW 343, CPAN 3004, SARBATI SONORA, DBW 17, HW 2004, UP 2425, DWR 16, NP 715, GW 496, UP 1109, HD 2135, WH 711, WH 1105, PBW 443, VL 404, SONORA 64, HD 2687, DURGAPUR 65, UP 2121, PBW 175, RAJ 3765, K 65, PBW 373, HD 2281 and VL 421) exhibited value of ' $r$ ' between 0.100 1.70. Ali et al. (2008) observed a strong association between the coefficient of infection $(\mathrm{Cl})$ and final rust severity (FRS) and concluded that wheat varieties having lower FRS value exhibiting slow rusting (partial resistance) against the Puccinia striiformis. Dehghani and
Moghaddam (2004) also showed that wheat lines, which had low values of FRS at adult plant stage, exhibited durable resistance (slow rusting or high-temperature adult plant resistance) for a long time, even if pathogen mutated because it is governed by minor genes. Parlevliet (1988) recorded that breeding lines with low value of AURPC, $r$ AURPC, Cl and ' $r$ ' were expected to possess genes that conferred partial resistance.

\section{Molecular characterization by using alleles - specific primer}

Twenty three varieties (DWR 16, PBW 343, VL 616, DBW 16, WH 711, GW 496, UP 2121, HD 2687, PBW 175, HD 2135, HS 240, HW 2045, RAJ 1482, PBW 550, UP 2425, PBW 443, WH 1105, SONALIKA, PBW 154, HD2967, RAJ 3077, RAJ 3765 and HD 2864) amplified a band of $517 \mathrm{bp}$ while remaining varieties (SONARA 64, HD 2281, DURGAPUR 65, WH 542, VL 421, K 65, CPAN 3004, RSP 561, HD 2307, SARBATI SONORA, HD 2404, DBW 621-50, PBW 373, JAUW 584, WH 533, RAJ 821, UP 1109, VL 804, LAL BAHADUR, DBW 17, HW 2004, VL 404, HD 2824, AGRA LOCAL, NP 715, KALYAN SONA and HD 2329) didn't amplify any band (Fig. 1). The amplification of a band of $517 \mathrm{bp}$ indicated the presence of $Y r 18$ gene which is in agreement with Lagudah et al. (2006). Locus Lr34/ Yr18 confers partial and durable resistance against the multiple fungal pathogens viz., leaf rust, stripe rust and powdery mildew and showed that alleles of resistant and susceptible cultivars differed by only three sequence polymorphism and characterized as diagnostic molecular marker that would assist the selection for durable multiple-pathogen resistance (Pathan et al., 2007; Lagudah et al., 2009).

\section{Effect of foliar application of various fungicides on the severity of stripe rust in different varieties of wheat}

Data in Table 2 revealed that during 2013-14 and 201415 all the fungicides were significantly effective reducing the severity of stripe rust of wheat as compared to untreated controls (51.25\%). The fungicide Amistar Top was most effective having the minimum mean disease severity in all the test varieties viz., HD 2967 (7.41\%), DPW 621-50 (12.75\%), RSP 561 (13.71\%) and PBW 343 (19.35) which was followed by Quadrix $(8.10,17.33$, 18.63, 28.71\%), Score (11.05, 23.63, 25.45, 39.34\%), Folicur $(12.19,26.33,28.80,45.30 \%)$ and Tilt (13.46, ,30.19, 33.59 and $52.65 \%$ ) in wheat varieties HD 2967, RSP 561, DPW 621-50 and PBW 343, during both the cropping season. Application of Triadimefon, Fenarimol, Benomyl, and Oxycarboxin was effective to control the stripe and leaf rust of wheat (Wanyera et al., 2010). Ahanger et al. (2014) recorded that Quadrix (0.1\%) proved most effective in reducing disease severity of stripe rust in susceptible varieties as compared to moderate resistant varieties. Loughman et al. (2005) observed that foliar fungicides achieved economic control only when applied at an early stage of disease initiation as early intervention reduced damage and ensured translocation of nutrients for proper grain filling. Han et 


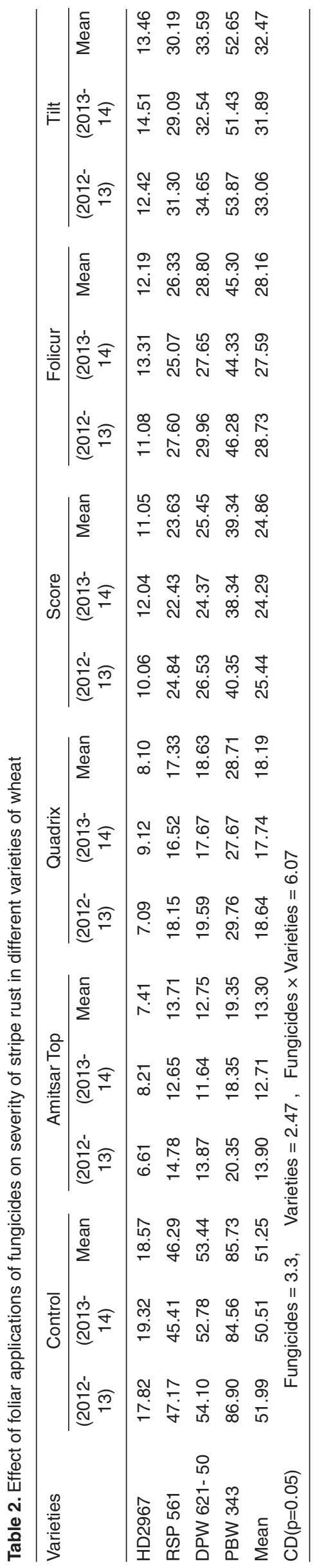

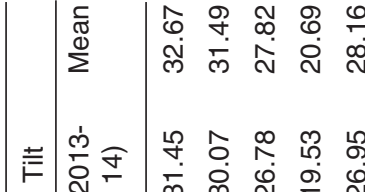

ง่

选

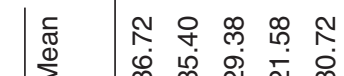

芦

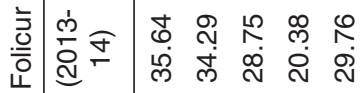

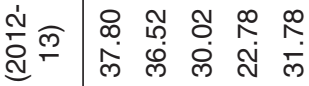

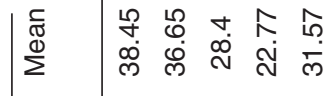

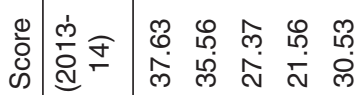

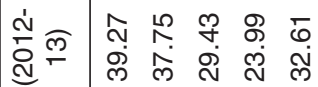

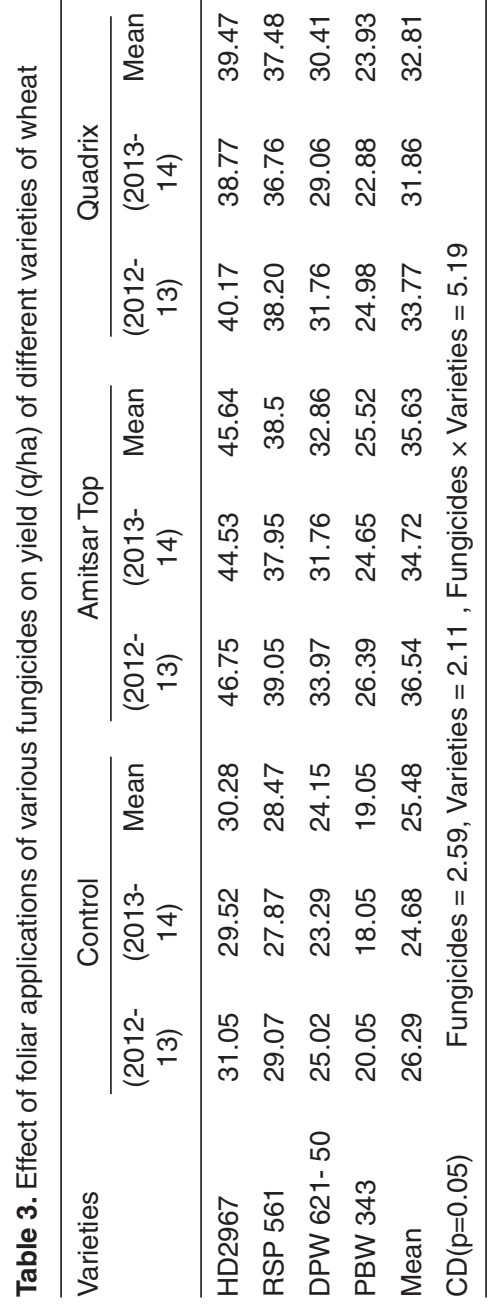



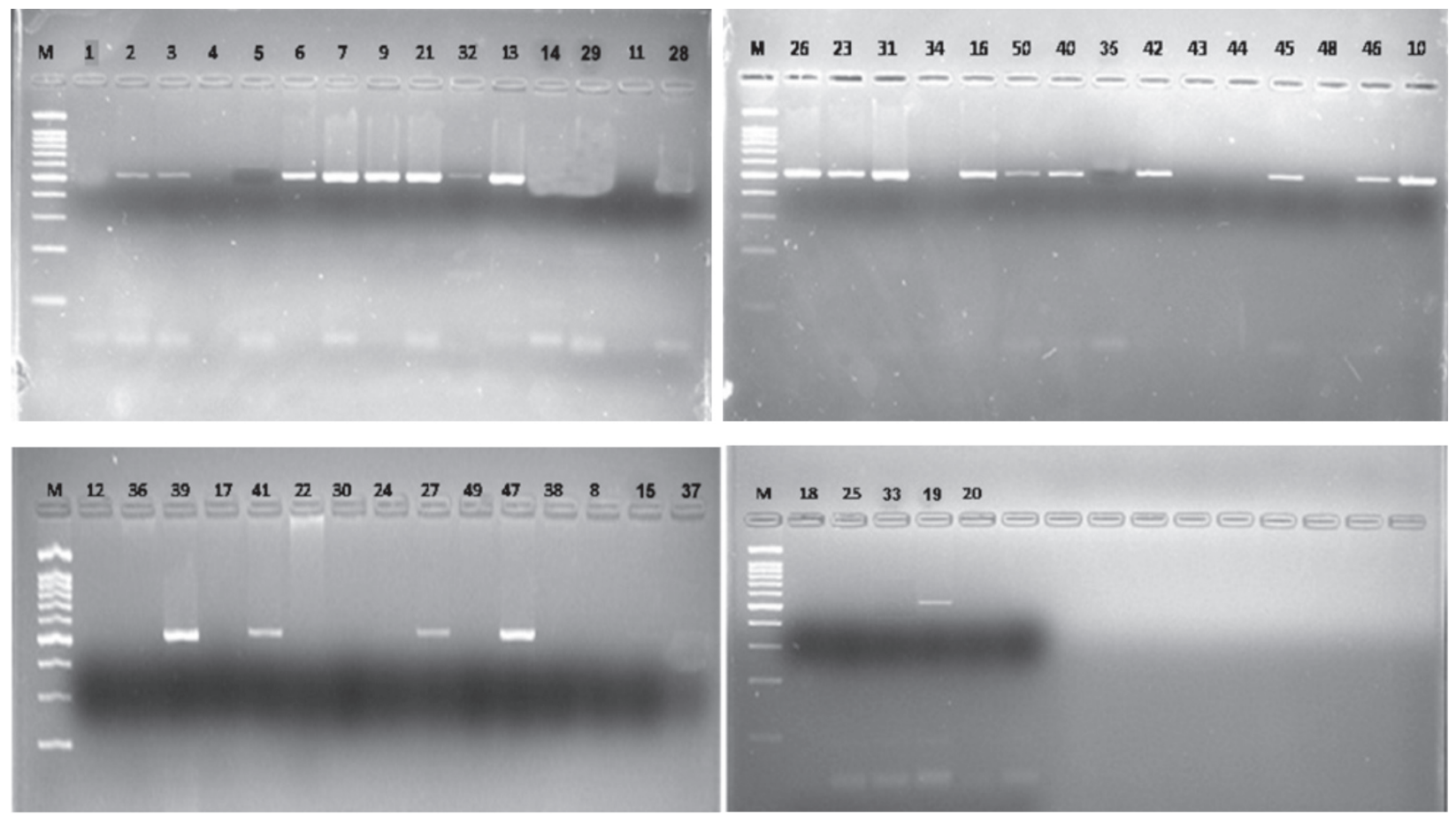

Fig. 1. PCR amplification of 50 wheat varieties with cssfr1 showing amplification of 517 bp band. M - Ladder, Samples - 1 (SONARA 64), 2 (DWR 16), 3 (PBW 343), 4 (HD 2281), 5 (DURGAPUR 65), 6 (VL 616), 7 (DBW 16), 8 (WH 542), 9 (WH 711 ), 10 (GW 496), 11 (VL 421), 12 (K 65), 13 (UP 2121), 14 (cPAN 3004), 15 (RSP 561), 16 (HD 2687), 17 (HD 2307), 18 (SARBATI SONORA), 19 (PBW 175), 20 (HD 2404), 21 (HD 2135), 22 (DBW 621-50), 23 (HS 240), 24 (PBW 373), 25 (JAUW 584), 26 (HW 2045), 27 (RAJ 1482), 28 (WH 533), 29 (RAJ 821), 30 (UP 1109), 31 (PBW 550), 32 (UP 2425), 33 (VL 804$), 34$ (LAL BAHADUR), 35 (DBW 17), 36 (HW 2004), 37 (VL 404), 38 (HD 2824), 39 (PBW 443), 40 (WH 1105), 41 (SONALIKA), 42 (PBW 154), 43 (AGRA LOCAL), 44 (NP 715), 45 (HD 2967), 46 (RAJ 3077), 47 (RAJ 3765), 48 (KALYAN SONA), 49 (HD 2329 ), 50 (HD 2864)

al. (2006) observed that fungicide, Tebuconazole, not only inhibited the development of $P$. striiformis in wheat leaves but also accompanied several morphological and structural changes in the hyphae and haustorium and increased vacuolation, irregular cell wall thickening and necrosis or degeneration of cytoplasm. They further recorded enhanced biochemical host defense reactions in the infected host by the accumulation of the two enzymes (chitin and $\beta$-1,3-glucanase) and lignin after fungicidal treatment.

\section{Effect of foliar application of various fungicides on yield of different varieties of wheat}

The data presented in Table 3 revealed that in HD 2967 maximum yield of $45.64 \mathrm{~g} / \mathrm{ha}$ was recorded by application of Amistar Top during both the cropping season which was significantly superior to Quadrix ( $39.47 \mathrm{q} / \mathrm{ha}$ ) followed by Score $(38.45 \mathrm{q} / \mathrm{ha})$, Folicur $(36.72 \mathrm{q} / \mathrm{ha})$ and Tilt $(32.67 \mathrm{q} / \mathrm{ha})$, whereas in untreated control mean grain yield was $(30.28 \mathrm{q} / \mathrm{ha})$. Similarly, in other varieties viz., RSP 561, DPW 621-50 and PBW 343, application of Amitsar Top resulted in maximum mean yield of (38.50, 32.86 and $25.52 \mathrm{q} / \mathrm{ha}$ ) followed by Quadrix with (37.48, 30.41 and $23.93 \mathrm{q} / \mathrm{ha})$, Score with $(36.65,28.40$ and $22.77 \mathrm{q} / \mathrm{ha})$, Folicur $(35.40,29.38$ and $21.58 \mathrm{q} / \mathrm{ha})$ and Tilt (31.49, 27.82 and $20.69 \mathrm{q} / \mathrm{ha}$ ), respectively. The result was in conformity with the findings of Lopez et al. (2014) who recorded increased yield in wheat cultivars by the application of Tebuconazole. Singh et al. (2016) recorded that stripe rust was controlled by azoles and strobilurin group of fungicides, which also increased the grain yield and quality.

\section{REFERENCES}

Ahanger RA, Gupta V, Bhat HA and Dar NA (2014). Management of yellow rust (Puccinia striiformis West) of wheat and its impact on yield under Jammu sub-tropics of India. The Bio. 9: 215-218.

Ali S, Shah SJA and Maqbool K (2008). Field-based assessment of partial resistance to stripe rust in wheat varieties. J. Agri. Rural Dev. 6: 99-106.

Chen XM (2005). Epidemiology and control of stripe rust (Puccinia striiformis f. sp. tritici) on wheat. Can. J. Plant Pathol. 27: 314-337.

Chen XM (2007). Challenges and solutions for stripe rust control in the United States. Aust. J. Agric. Res. 58: 648-655.

Dehghani $\mathrm{H}$ and Moghaddam M (2004). Genetic analysis of the latent period of stripe rust in wheat seedling. J. Pathol. 122: 325-330.

Farrokhi J, Darvishzadeh R, Naseri L, Azar M and Hatami H (2011). Evaluation of genetic diversity among Iranian apple (Malus domestica Borkh.) cultivars and landraces using simple sequence repeat markers. Aust. J. Crop Sci. 5: 815821.

Gupta V, Ahanger RA, Razdan VK, Sharma BC, Singh I, Kaur $\mathrm{K}$ and Pandey MK (2013). Prevalence and distribution in different agro-ecologies and identification of resistance source of wheat stripe rust. Afr. J. Agric. Res. 8: 3268-3275. 
Han QM, Kang ZS, Buchenauer H, Huang LL and Zhao J (2006). Cytological and immune cyto-chemical studies on the effects of the fungicides tebuconazole on the interaction of wheat with stripe rust. J. Pathol. 88: 263-271.

Herrera-Fossel SA, Singh RP and Huerta-Espino J (2007). Evaluation of slow rusting resistance components of slow rusting resistance components to leaf rust in International maize and wheat improvement centre durum wheat. Euphytica. 155: 361-369.

Lagudah ES, Krattinger SG, Foessel SH, Singh RP and Espino $\mathrm{FH}$ (2009). Gene-specific markers for the wheat gene LB34/ Yr18/Pm38 which confers resistance to multiple fungal pathogens. Theor. Appl. Gent. 119: 889-898.

Lagudah ES, Mc Fadden H, Singh RP, Huerta-Espino J, Banana HS and Spielmeyer W (2006). Molecular genetic characterization of the $L r 34 / Y r 18$ slow rusting resistance gene region in wheat. Theor. Appl. Gent. 114: 21-30.

Lopez JA, Rojas K, Teresa CD, Jin H and James S (2014). Foliar fungicide application in North east Texas: Yield response \& profit ability. Southern Agricultural Economics, Texas. 120, pp.

Loughman R, Jayasena K and Majewski J (2005). Yield loss and fungicides control of stem rust of wheat. Aust. J. Agric. Res. 56: 91-96.

Parlevliet JE (1988). Strategies for the utilization of partial resistance for the control of Cereal Rusts. International maize and wheat improvement centre, Mexico 48-62 pp.

Pathan AK and Park RF (2006). Evaluation of seedling and adult plant resistance in wheat resistance in wheat linesto Puccinia striiformis f. sp. tritici. Euphytica 149: 327-342.

Pathan AK, Park RF, Wellings CR and Bariana HS (2007). The expression and genetics of resistance to stripe rust in three
European and four New Zealand wheat cultivars. J. Appl. Gen. 48: 199-210.

Peterson RF, Campbell AB and Hannah AE (1948). A diagrammatic scale for estimating rust intensity of leaves and stem of the cereals. Can. J. For. Res. 26: 496-500.

Prashar M, Bhardwaj SC, Jain SK. and Datta D (2007). Pathotypic evolution in Puccinia striiformis in India during 1995-2004. Aust. J. Crop Sci. 58: 602-604.

Seah S, Sivasithamparam K, Karakousis A and Lagudah ES (1998). Cloning and characterization of a family of disease resistance gene analogs from wheat and barley. Theor. Appl. Gent. 97: 937-945.

Selvakumar R, Madhumeeta, Shekhawat PS, Verma RPS and Sharma I (2014). Management of stripe rust of barley using fungicides. Indian Phytopath. 67: 138-142.

Shah SJA, Muhammad I and Hussain S (2010). Phenotypic and molecular characterization of wheat for slow rusting resistance against Puccinia striiformis Westend. f. sp. tritici. J. Phytopathol. 158: 393-402.

Singh RP, Huerta-Espino J, Bhavani S, Herrera-Foessel SA, Singh D, Singh PK, Velu G, Mason RE and Crossa J (2002). Race non-specific resistance to rust diseases in International maize and wheat improvement centre, Mexico spring wheat. Euphytica 179: 175-186.

Singh VK, Mathuria MC, Gogoi R and Aggarwal R (2016). Impact of different fungicides and bioagents, and fungicidal spray timing on wheat stripe rust development and grain yield. Indian Phytopath. 69: 357-362.

Wanyera R, Macharia JK and Kilonzo SM (2010). Challenges of fungicides control on wheat rusts in Kenya. Kenya Agriculture Research Institute, Kenya 123-138 pp. 